\title{
A LINGUAGEM NULA: UMA LEITURA FILOSÓFICA DA POESIA DE SARA SÍNTIQUE
}

\section{THE NULL LANGUAGE: A PHILOSOPHICAL READING OF SARA SÍNTIOUE' POETRY}

\author{
Fernando de Mendonça²
}

RESUMO: Com o objetivo de iluminar a obra da jovem poeta cearense Sara Síntique, autora dos livros Corpo Nulo (2015) e Água ou Testamento Lírico a Dias Escassos (2019), apropriamo-nos da perspectiva fenomenológica de Gaston Bachelard sobre as propriedades poéticas da água (1942), assim como das reflexões que Maurice Blanchot (1959) delineia a partir de uma genealogia da linguagem poética nula. Ressaltamos em nossa leitura o apreço simbólico da autora por imagens e reflexos que irmanam a palavra poética ao corpo feminino, destacando o caráter metalinguístico de sua produção, autocentrada em uma busca primeira pela neutralidade da linguagem.

PALAVRAS-CHAVE: Poesia Brasileira Contemporânea. Autoria Feminina. Literatura e Filosofia. Fenomenologia da Água. Sara Síntique.

ABSTRACT: With the objective to illuminate the work of the young poet Sara Síntique, was born in Ceará, authoress of the books Corpo Nulo (2015) and Água ou Testamento Lírico a Dias Escassos (2019), we have appropriated Gaston Bachelard's phenomenological perspective on the poetic properties of water (1942), as well as the reflections that Maurice Blanchot (1959) outlines from a genealogy of the null poetic language. In our reading, we emphasize the symbolic appreciation for images and reflections that approach the poetic word to the female body, detaching the metalinguistic character of her production, self-centered in a first search for the neutrality of language.

KEYWORDS: Contemporary Brazilian Poetry. Female Authorship. Literature and Philosophy. Water Phenomenology. Sara Síntique.

\footnotetext{
${ }^{1}$ Artigo recebido em 10 de março e aceito em 10 de abril de 2021.

2 Doutor em Letras pela UFPE; Professor Adjunto na UFS (DELI/PPGL/PPGCINE); Membro do Núcleo de Estudos em Literatura e Intersemiose (NELI - UFPE) e do Grupo de Estudos em Filosofia e Literatura (GEFELIT - UFS); 1ㅇ Secretário do Grupo de Estudos Linguísticos e Literários do Nordeste (GELNE) e Coordenador do Centro Internacional e Multidisciplinar de Estudos Épicos (CIMEEP). E-mail: nandodijesus@gmail.com. ORCID: https://orcid.org/0000-0002-8659-8490.
} 


\section{Introduçào}

É sempre desafiadora a dedicação de um olhar crítico a itinerários artísticos e literários que ainda estejam em desenvolvimento, pela emergência de suas transformações e desconhecimento dos percursos ainda futuros, a serem decididos e evidenciados por obras que estejam em construção. Falar sobre artistas e poetas em vida, além do benefício na divulgação de seus trabalhos, pode se constituir como um gesto decisivo para determinados contornos a serem abraçados pelo público leitor, no sentido de permitir um direcionamento interpretativo prévio, como também de significar um impulso na autoconscientização da voz poética que se permita receber o retorno crítico como um mecanismo a contribuir na problematização e perpetuação de sua obra, algo naturalmente salutar, considerando-se que a voz da autoria poética também se efetiva como sua primeira leitora - por mais paradoxal que seja a impossibilidade da leitura ideal, nesse sentido.

Estas páginas se dedicam a uma apresentação de cunho afetivo e filosófico da jovem poeta cearense, Sara Síntique, nascida em 1990 e autora, até o momento, de dois livros: Corpo Nulo (2015) e Água ou Testamento Lírico a Dias Escassos (2019), publicados, respectivamente, pela Editora Substânsia e pelas Edições Ellenismos. Além de atuar criativamente na escrita poética, Sara também é atriz e educadora ${ }^{3}$, o que agrega uma consciência performática à sua escritura, toda esta atravessada por diálogos e reflexões especulares que acentuam a perspectiva corporal a que se entregam seus poemas, num imediato sincronismo com a epiderme autoral de Sara, mas também numa espécie de eco a questões e anseios contemporâneos a respeito de temas, como: autoria feminina, literatura regional, poesia e performance, representações do corpo (da mulher e, mais amplamente, do humano), dentre outros.

\footnotetext{
${ }^{3}$ Para mais informações sobre a vida e a obra da artista, ver seu site pessoal: https://sintiquee. wixsite.com/sarasintique
} 

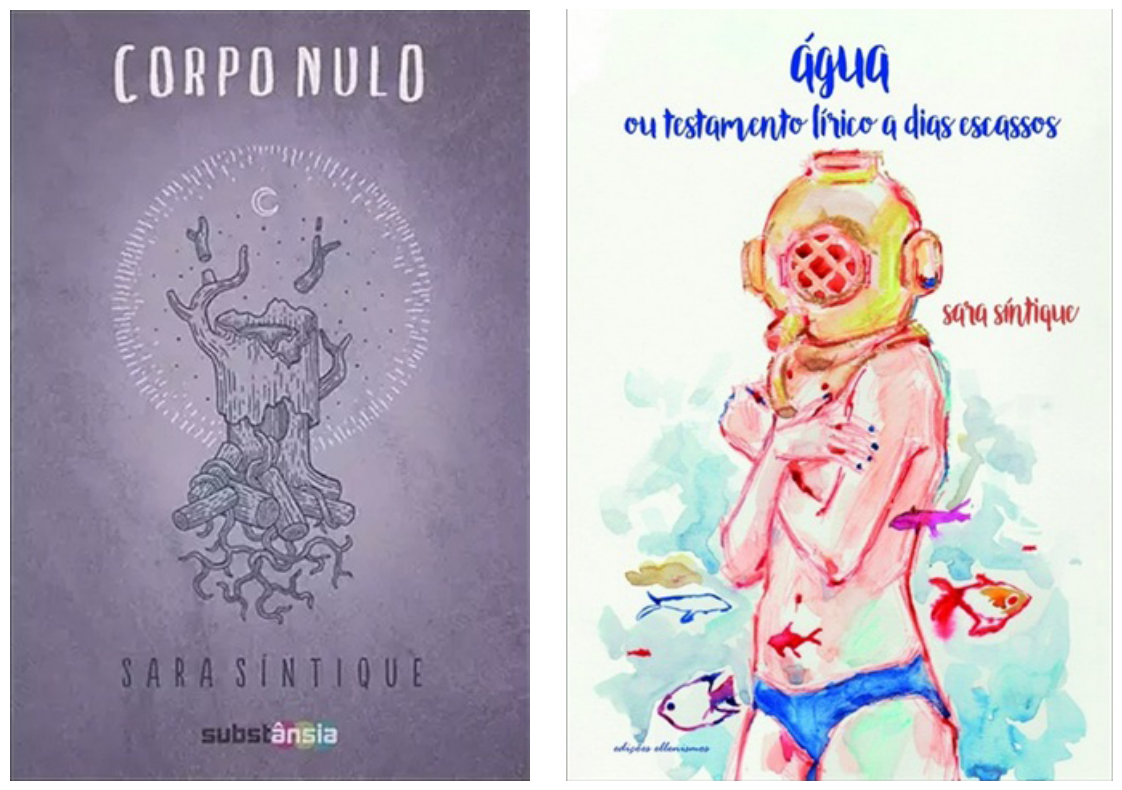

Reconhecemos nestes dois livros um potencial de leituras múltiplas, a serem certamente agregadas por novos e vindouros trabalhos de Sara. Por ora, atemo-nos a uma abordagem específica ao que já se pode evidenciar de maneira muito clara, pelo aprofundamento identificado na sequência destas primeiras publicações, voltada para uma apropriação de imagens das águas, na maneira como este imaginário define as propriedades da palavra poética. À luz de conceitos e simbolismos encontrados na fenomenologia das águas de Gaston Bachelard (1942), assim como de reflexões irmanadas a Maurice Blanchot (1959), sobre a palavra literária que objetiva o avesso da linguagem cotidiana, iluminaremos a apresentação desta jovem escritora, que tem renovado a poesia contemporânea brasileira de maneira muito pessoal e sensível, consciente de seu lugar e compromisso com o Verbo.

\section{Imaginaçồes da Matéria da Água}

Considerando a ainda restrita circulação dos livros de Sara Síntique, e para melhor conduzir a leitura aqui proposta, dispomos a seguir dois poemas da autora, transcritos, um de cada obra, e selecionados a partir de uma identificação mais efetiva junto aos temas e imagens que pretendemos refletir: 


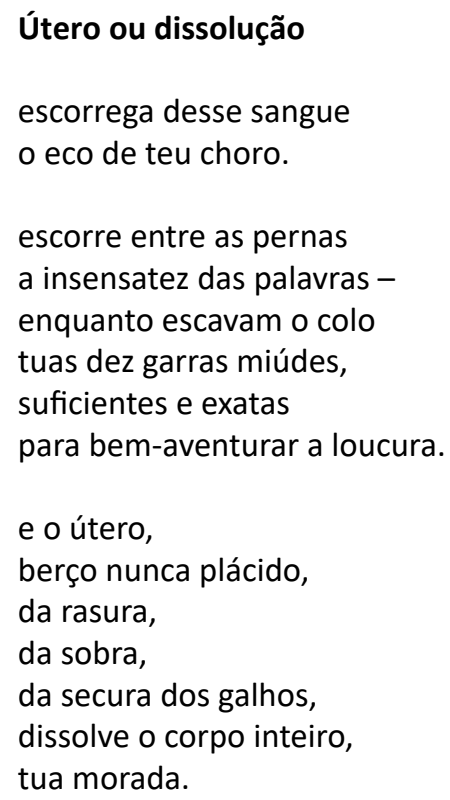

\section{Subterrânea}

habitar um chão e sua impermanência

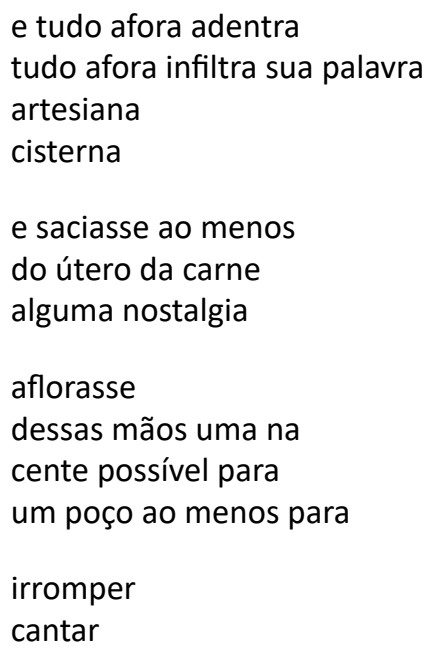

(SÍNTIQUE, 2019, p. 10).

Trata-se de dois poemas que mantêm contígua relação e que ilustram diretamente nosso interesse interpretativo, na maneira como exploram as dimensões do corpo-palavra por meio de variações da matéria da água. Que se observe, de imediato, a expressiva recorrência vernacular às imagens líquidas, no que evocam de uma percepção e identificação corporal que transcende as qualidades semânticas para o surgimento de conexões e espeIhamentos imprevistos. A maneira como o tema uterino se desenvolve, aliançando os dois textos - e livros -, chama atenção pela força simbólica que situa o corpo poemático de Sara Síntique ao que primeiramente se localiza no corpo de mulher, já indicando que em gestação se encontram não apenas os corpos, mas também as palavras que deles fluem.

São poemas que se equilibram em potências de (in)visibilidade, seja pela palavra que se associa ao interno órgão feminino, de maneira mais incisiva no primeiro texto, como pela palavra subterrânea que já intitula o texto seguinte. Do útero ao que se enraíza como artesiano, alternam-se efeitos de movimentos que não são objetivamente visíveis, mas que se realizam e fertilizam novas possibilidades de sentido para a habitação da palavra poética. Não por acaso, conjugarem-se verbos tão significativos para este enlace de palavras que 
também são corpos aquáticos, em referência ao uso de escorrer, no primeiro texto, e infiltrar, no segundo. Despertar a palavra em sua força artesiana, como de águas que fluem bem abaixo de nós, é localizar a palavra enquanto algo que continua sob nós, mas sem que vejamos claramente. É preciso que haja uma disposição para escavá-las e para que elas aflorem como uma nascente possível.

Aqui, já notamos um pendor fenomenológico da experiência poética, pela relação que tal uso e consciência de linguagem podem irmanar junto aos pensamentos de Merleau-Ponty, pois, temos no corolário de $O$ Visível e O Invisível (original de 1964) que a abertura do horizonte ao nomeável e ao dizível problematiza o silêncio - logo, o invisível da palavra - manifestando uma existência quase carnal da ideia, assim como permitindo uma sublimação da carne. As discussões do pensador sobre a carnalidade do tempo, do que vemos e do que dizemos, partem igualmente de uma concepção arquitetônica do corpo humano que aqui localizamos como partícipe ao projeto poético de Sara Síntique. Ambos se remetem a corpos que exploram e ocupam o 'avesso do mundo', fundindo propriedades anatômicas ao ser da palavra, que, "quando metamorfoseia as estruturas do mundo visível, se torna olhar do espírito". (MERLEAU-PONTY, 2014, p. 149). Ora, no princípio ontológico de que as palavras nos dão coisas inacessíveis aos olhos - como o útero da mulher e a nascente artesiana de um poço, para ficarmos nas imagens dos versos lidos - compreendemos uma dimensão que atravessa o cerne da palavra poética. Nesse sentido, a potência metamórfica acima destacada também nos orienta ao encontro de outro fenomenólogo, sobre o qual nos concentramos mais a fundo para reverberar o encontro das águas na poesia de Sara, afinal: "A água é também um tipo de destino (...) um destino essencial que metamorfoseia a essência do ser." (BACHELARD, 2018, p. 6).

Em uma de suas obras consagradas à imaginação da matéria $^{4}$, através dos elementos básicos da natureza, Gaston Bachelard desenvolve uma série de aplicações e reflexões simbólicas sobre o psiquismo hidrante, na literatura e nas artes. A Água e Os Sonhos demarca um mergulho de fôlego às forças imaginantes de ordem hídrica, cujo objetivo é posto desde suas primeiras palavras: "es-

${ }^{4} \mathrm{O}$ mesmo filósofo classificou e aprofundou, sucessivamente, as imagens do fogo, do ar e da terra (elementos materiais que a filosofia, as ciências antigas e a alquimia, colocaram na base de todas as coisas), através das obras A Psicanálise do Fogo (1937), O Ar e Os Sonhos (1943) e A Terra e Os Devaneios da Vontade / A Terra e Os Devaneios do Repouso (1948). 
cavar o fundo do ser; encontrar no ser, ao mesmo tempo, o primitivo e o eterno." (BACHELARD, 2018, p. 1). Onde localizamos uma convergência direta para com o que motiva a poesia de Sara Síntique e, como bem vimos, sua capacidade de escavar as dimensões materiais da palavra e do ser.

Com o intuito de melhor evidenciar a pertinência das investigações aquáticas na obra de Sara, cabe salientar o exponencial avanço que a autora empreende na passagem do primeiro para o segundo livro, em seu repertório de imagens aquáticas. Na coletânea de 2015 , como vimos exemplificado pelo poema transcrito daquela obra, já subsistia uma variedade de imagens que se valiam do psiquismo hidrante; uma observação do poema que selecionamos na publicação de 2019, por sua vez, permitiu a percepção de que as alusões ao imaginário das águas agora se ofertam exatamente em dobro. Na tabela a seguir, para facilitar tal identificação vernacular, dispomos um comparativo das palavras hídricas colhidas nos dois poemas (três no primeiro, seis no segundo), com um destaque aos dois verbos que fundem a matéria da palavra dentro de propriedades líquidas (o que retomaremos mais adiante), para finalmente coletar uma amostragem geral do quantitativo de termos oriundos das formas líquidas, e assim verificarmos a importância crescente destas materialidades para o fazer poético da escritora:

\begin{tabular}{|l|l|}
\hline Corpo Nulo & Água ou Testamento Lírico... \\
\hline Sangue / Choro / Útero & $\begin{array}{l}\text { Rio / Artesiano / Cisterna / Nascente } \\
\text { / Poço / Útero }\end{array}$ \\
\hline Escorre (a palavra) & Infiltra (sua palavra) \\
\hline & $\begin{array}{l}\text { Onda / Alagada / Barragem / Chuva } \\
\text { / Oásis / Sereia / Gota / Lágrima / }\end{array}$ \\
& $\begin{array}{l}\text { Geleira / Mar / Inundação / Suor / } \\
\text { Banho / Cachoeira / Sangue / Ácido / } \\
\text { Nevoeiro / Vapor / Poça / Naufrágio } \\
\text { / Oceano / Orla / Café / Sede / Colí- } \\
\text { nho / Gota / Sereia } \\
\text { rio / Gole / Saliva / Dilúvio / Líquido } \\
\text { / Bacia / Enxurrada / Riacho / Batis- } \\
\text { mo / Unção / Pia / Garoa / Neblina } \\
\text { / Chuvisco / Mijo / Vinho / Lama / } \\
\text { Cuspe / Hídrico / Cântaro }\end{array}$ \\
\hline
\end{tabular}


A expressiva ampliação no leque de palavras e imagens líquidas (descontados os dois verbos, a tabela contabiliza dez palavras no primeiro livro e cinquenta no segundo) não deixa dúvida do direcionamento tomado pela poeta, no literal sentido de transbordar variações linguísticas e simbólicas de um psiquismo hidrante. Ainda cabe destacar que, pela restrição destas páginas, optamos por não incluir no quadro acima uma série de outras locuções que também se afinam ao contexto das águas, como o prolífico uso de verbos (a exemplo de fluir, afogar, submergir, lavar, molhar, beber, escoar etc.) e a acentuada recorrência a elementos que, apesar de não materialmente líquidos, só encontram sentido dentro deste campo semântico (a exemplo de navio, barco, ponte, peixe, pescador, garrafa etc.). A bem da verdade, nossa apresentação deste vocabulário, limita-se por ora a apenas indicar possibilidades analíticas vindouras, pois disso nos valemos para melhor problematizar as relações imagéticas de sua fonte poética com as considerações de Bachelard.

Apesar de assumir intenções mais ambiciosas do que as restritas pelo viés psicanalítico - como fizera em sua abordagem ao fogo -, o filósofo não nega o caráter subjetivo e íntimo das substâncias aquáticas, reconhecendo que as águas guardam e sabem todos os segredos do inconsciente humano. $O$ que ele identifica no incessante 'mobilismo heraclitiano' é um tipo de 'sofrimento infinito' que se irmana ao da consciência criante, mais diretamente ligada à criação poética, pois o sofrimento da escrita é também provado numa escala de infinitude. Dentre as inúmeras características postuladas a respeito da matéria da água, destacamos a seguir duas classificações específicas, pelos fundamentais ecos que ressoam na obra de Sara Síntique:

a) As águas são essencialmente femininas: num contraponto ao que norteará sua abordagem masculina da terra, a fenomenologia dos elementos naturais localiza a 'matéria feminina' inteiramente situada nas águas, que tornaram "a propriedade da substância feminina dissolvida (...) A água leva-nos. A água embala-nos. A água adormece-nos. A água devolve-nos a nossa mãe." (BACHELARD, 2018, p. 134-36). Como vimos, Sara universaliza regiões e funções do corpo da mulher, materializando e associando a qualidade fertilizante das palavras a de um corpo materno que traz em si a potência de gerar vida. Em poesia, a palavra é um ente que, 
além de nomear e evocar realidades, também se refrata e dilui em múltiplas gerações de sentido, não estanques e continuamente renováveis (mobilismo heraclitiano);

b) As águas são essencialmente narcísicas: justificadas as motivações fenomenológicas na tentativa de se desvendar a consciência criante, o mito narcísico vem se estabelecer como um dos principais para a inspiração na qualidade reflexiva/espelhante das águas, pois "o espelho da fonte é motivo para uma imaginação aberta. Diante da água, Narciso sente que sua beleza continua, que ela não está concluída." (BACHELARD, 2018, p. 24). Tal caráter de abertura e de permanente incompletude dos sentidos, natural ao fazer poético, também ganha contornos maiores na obra de Sara Síntique, pois a postura narcísica de seus versos, no foco autorreflexivo de uma poesia que se problematiza criando, permite-nos constatar serem as águas destes dois livros grandes espelhos a emoldurarem possibilidades de linguagem para a poesia contemporânea e seus processos de produção.

De onde retornamos para os verbos escorrer e infiltrar, responsáveis, dentro dos poemas que aqui têm nos servido de exemplo, a uma conexão do psiquismo hidrante com a prática de uma poética autoconsciente que não deixa de refletir a matéria criativa escritural. No uso que estes verbos evocam de palavras tornadas águas, exacerbam-se as propriedades de palavras que também são espelhos, translúcidas superfícies agora aptas a nos conduzirem para uma reflexão da linguagem nula, o que identificamos ser a maior ambição poética desta jovem autora, e o que a conecta a uma moderna tradição estilística que lhe é tão cara e fundante.

\section{Anulamento da Linguagem}

Os dois livros de Sara Síntique, para não abandonarmos a referência narcísica estabelecida, sob vários aspectos podem ser iluminados como um sendo o espelho do outro, ainda que sob um prisma deformante e autorregulador. Assim os definimos, inclusive, por conta do adensamento temático que constatamos no exemplo da coleta de termos hídricos. Afinal, se o segundo livro espelha o imaginário das águas numa proporção ao menos cinco vezes maior ao que o anterior apresentou, temos aí um reflexo 
não transparente, pois capaz de efeitos ampliadores. Nesse sentido, cabe lembrarmos a contribuição legada por Umberto Eco em torno da função que os espelhos deformantes agregam ao prazer estético. Segundo suas teorias da especularidade artística, esse tipo de relação espelhada coloca a consciência em um estado de 'férias pragmáticas': "Há um 'saber mais' sobre o que sou ou poderia ser, uma aurora de exercício contrafactual, um início de semiose." (ECO, 1989, p. 33).

Destacamos a qualidade especular dos livros de Sara com o objetivo de iluminar suas próprias palavras como em estado permanente de 'aurora', de renascimento constante e mergulhadas no claro propósito de ofertar uma linguagem em estado de autodescoberta. Não por acaso, Corpo Nulo e Água ou Testamento Lírico... subsistem enquanto publicações que se pretendem, numa condição ontológica, de ser uma o negativo imediato da outra. Além de as duas coletâneas serem numericamente formadas pela exata quantia de 33 poemas, cada uma, é reveladora a decisão de Sara ao abrir o primeiro livro, e fechar o segundo, com epígrafes de Hilda Hilst que exploram a autoconsciência da palavra poética, em seu estado de nudez e capacidade de inquietação - e que se registre vir a expressão Testamento Lírico do exato poema transcrito de Hilst. Como vemos, desde os títulos de seus livros, Sara problematiza um diálogo com antepassados literários, onde localizamos no adjetivo do primeiro (Nulo), uma chave para a interpretação de toda a sua poética.

A tabela a seguir coleta mais uma amostragem de fragmentos, nos poemas dos dois livros, onde a dinâmica da palavra e do silêncio é trazida ao primeiro plano:

\begin{tabular}{|l|l|}
\hline Corpo Nulo & Água ou Testamento Lírico... \\
\hline 'me quero silêncio' (p. 17) & $\begin{array}{l}\text { 'aquele medo de esquecer } \\
\text { todas } \\
\text { as palavras' (p. 17) }\end{array}$ \\
\hline $\begin{array}{l}\text { 'tento nas palavras } \\
\text { um sinal, uma prece' (p. 26) }\end{array}$ & $\begin{array}{l}\text { 'e uma palavra que fosse adubo gota } \\
\text { semente } \\
\text { e uma palavra que fosse terra dentro } \\
\text { além } \\
\text { uma palavra além } \\
\text { não há.' (p. 18) }\end{array}$ \\
\hline
\end{tabular}




\begin{tabular}{l|l|}
$\begin{array}{l}\text { 'teu nome líquido na minha boca' (p. } \\
\text { 30) }\end{array}$ & $\begin{array}{l}\text { 'qualquer palavra que sangrasse: } \\
\text { destruísse.' (p. 19) }\end{array}$ \\
\hline $\begin{array}{l}\text { 'não me digas nada sobre, } \\
\text { nada, } \\
\text { apenas um sempre } \\
\text { um sim' (p. 40) }\end{array}$ & $\begin{array}{l}\text { 'palavra risco } \\
\text { pois que me sabes } \\
\text { tremeluzente }\end{array}$ \\
\hline $\begin{array}{l}\text { 'ou as palavras } \\
\text { nada, nada } \\
\text { eu não alcanço' (p. 46) }\end{array}$ & $\begin{array}{l}\text { 'atreve-me. } \\
\text { Inventa uma nova língua' (p. 25) }\end{array}$ \\
\hline
\end{tabular}

Por questão de espaço, restringimos apenas cinco alusões colhidas em cada livro de específicos momentos onde vemos as motivações de uma linguagem em processo de neutralização ser mais diretamente colocada. Da primeira obra, como já indicado pelo título, o caráter nulo de um corpo se revela em plena consonância aos ideais da escritura nutridos por sua autora. Palavras inalcançáveis, querência de silêncio, liquidez de nomes, verbos que nada dizem, mas apenas se ofertam em condição de perene tentativa, todos os excertos acima denotam uma ambição poética que também se confirma e adensa no livro seguinte. Como a segunda coluna demonstra, o Testamento Lírico de Sara transita e se equilibra na fronteira entre a geração do novo e a destruição do antigo, entre a memória e o esquecimento, entre a fertilidade e a sequidão de palavras que, por sua identificação com as águas nascentes, orientam uma verdadeira revolução da língua, agora manifesta em estado de invenção. Não por acaso, este é um livro onde se elidem certezas mediante o uso mais acentuado de dualidades, paradoxos, ambiguidades e polissemias. A tessitura das palavras amplifica a ausência e o vazio buscados no primeiro livro de Sara, confirmando uma consciência potencial de linguagem que se anuncia por vir, inconclusa.

Muito certamente, a perspectiva crítica também abraçada pela poeta em sua vivência acadêmica ${ }^{5}$, com as teorias modernas da linguagem literária, foi basilar para o desenvolvimento e avanço de inquietações poéticas, na maneira como elas se evidenciam pela sucessão de seus dois livros. O contato com autores como

${ }^{5}$ Sara defendeu sua dissertação de Mestrado em Letras pela UFC, em 2017, quando tivemos a
oportunidade de contribuir em sua banca, sobre o trabalho Amar: partir-corpo e encontro amoro-
so na obra de Marguerite Duras, disponível em: http://www.repositorio.ufc.br/handle/riufc/40177 
Maurice Blanchot e Roland Barthes, em sua formação científica e afetiva, revela-se hoje fundamental para uma leitura da própria Sara, que atualiza inúmeros anseios emergentes do século passado e ainda vivos no espírito contemporâneo das letras. Nesse sentido, elegemos $O$ Livro Por Vir como um dos principais mapeamentos para a iluminação desta linguagem que se pretende nula, à espera de invenção: “(...) uma nulidade tão radical que, pela desmedida que ela representa, pelo perigo que ela beira e a tensão que provoca, exige, como para libertar-se, a formação de uma fala inicial com a qual serão afastadas as palavras que dizem alguma coisa." (BLANCHOT, 2005, p. 51).

Em sua reconstrução de uma perspectiva literária que remonta ao estado inaugural de uma obra como a de Mallarmé, este livro empreende uma espécie de genealogia do verbo nulo, situando a linguagem como um ponto de largada para materializações do que inexiste sem o poético. $O$ anulamento em questão, apesar de associado a um sentido de implosão e destruição semântica, tem o maior significado de possibilitar novos caminhos para a existência da palavra. Neutralidade e esvaziamento passam a simbolizar não mais uma aridez, mas uma abertura perene, um dissidente horizonte que localiza o futuro da linguagem no agora, no instante que se concretiza infinito: "A palavra poética pode suscitar as coisas e, traduzindo-as no espaço, torná-las manifestas por seu distanciamento e seu vazio (...) cabe à palavra trazer à luz, vazio que não se faz ver mas é presença luminosa, fissura pela qual se expande a invisibilidade." (BLANCHOT, 2005, p. 82-83).

Nesse sentido, resgatamos o registro de um revelador pronunciamento de Sara Síntique ${ }^{6}$, a respeito de sua compreensão do nulo, seu diálogo com outras teorias e a perspectiva que possui da palavra poética e de sua função neutra:

Às vezes, quando as palavras me chegam, eu tenho um ímpeto de silêncio, eu demoro muito a pensar (...) Muita gente me questiona sobre a palavra Nulo que eu uso no primeiro verso do livro (pois o título

\footnotetext{
${ }^{6}$ Em 21 de Outubro de 2020, Sara participou como convidada especial do 33ㅇe encontro do Clube de Leitura Criadora, que coordenamos como atividade de extensão na UFS, desde 2017. Na ocasião, foram apresentados e debatidos seus dois livros junto ao público, via modalidade remota, em diálogo com o romance de estreia de Clarice Lispector, Perto do Coração Selvagem (1943). A transcrição que fazemos de parte de sua fala contempla apenas as reflexões em torno de sua própria poesia, em restrição ao foco que aqui abordamos.
} 
de um livro não deixa de ser o seu primeiro verso). Eu me remeto muito ao corpo sem órgãos, que também remete ao zero. Eu gosto de fazer essa alusão do corpo como palavra e da palavra como corpo (como Barthes coloca em $O$ Prazer do Texto, sobre a palavra ser um corpo e não somente um corpo anatômico, da medicina, mas um corpo erótico). Nessa alusão, gosto de brincar com a polissemia. Eu penso muito no sentido do nulo em relação a algo que nega a norma, a conformidade de uma norma. Puxando isso para a palavra, nós (poetas) trabalhamos com um corpo que é extremamente desgastado o tempo todo, que usamos sempre para nos comunicarmos. A palavra, no cotidiano, está em seu mais puro desgaste. É diferente de um pintor que usa tintas, pois a tinta não é manuseada por todo mundo o tempo todo; diferente de uma argila, de uma pedra. Esse movimento é o de pensar uma palavra que não está à mercê do cotidiano, que não está à mercê de narrar alguma coisa dentro de um campo de lógica, de uma serventia; ela não contribui com a norma, com o sistema, mas ela provoca uma destruição da norma hegemônica [nesse sentido, o livro de Marguerite Duras, Destruir, Disse Ela é evocado pelo primeiro poema de Água ou Testamento Lírico...]. A palavra como corpo, um corpo que dança, como um corpo de teatro, também vem para quebrar a norma, o automatismo, o andar, o dormir e o acordar cotidianos, vem para se reinventar enquanto corpo. (...) Zerar o organismo e não a potência de cada órgão. Zerar a palavra que está à mercê e explorar o campo de poder que cada palavra tem, inclusive de destruir os pensamentos, as linguagens já constituídas. Um pensamento kafkiano me move muito: "Mais perigoso do que o canto das sereias, é seu silêncio". A sereia oferece o que há de mais belo, que é seu canto, mas também uma destruição pela morte. Se você não escuta o canto, não tem o contato nem com a beleza nem com a morte. Você perde muito. É uma loucura não escutar esse canto.

A experiência do corpo de mulher está muito forte na minha escrita. Em alguns poemas eu tento buscar uma neutralidade, um corpo mais amplo, não delimitado enquanto gênero. Mas a poesia passa imbricada pelo meu corpo. Não tenho como não pensar e mencionar esse corpo que gesta, que cria, esse corpo 
que é capaz de dissolver o seu filho e de dissolver-se na possibilidade de criação. Um corpo que menstrua, que sangra todo mês dizendo 'eu estou pronto para criar', é um aviso, e, ao mesmo tempo, um aviso de você não estar criando, gestando algo. Essa palavra me vem, essa que escorre, que ganha uma força de criação, mas não se sustenta, ela silencia antes de gestar por nove meses e parir-se. Ela silencia no sangue. [alusão ao verso que diz "eu me quero silêncio"] Eu sinto que existe no meu processo de escrita esse desejo de uma palavra que ecoa, que reverbera, mas ao mesmo tempo é opaca, ela não é transparente (como no conceito blanchotiano, da palavra com luminosidade de coisa). Eu não chego ao que ela quer dizer, ao desgaste cotidiano. Eu tento chegar ao seu princípio, como se a palavra tivesse acabado de ser talhada. 0 que é isso? O que é essa palavra? O que ela traz como imagem? E aí vem o desejo de inventar uma nova língua. Essa primeira língua, isso que eu ainda vou descobrir. Um bebê balbuciando suas primeiras palavras. Acho que o processo de criação literária está muito envolto nisso, nesse tato de descoberta primeira, e para isso, acho que tem sim que explodir com tudo, para poder brincar, para dançar com essa potência da palavra que a gente já desgasta tanto.

Penso, sim, nessa palavra que está abaixo das coisas, como a água que está abaixo das coisas. Eu queria muito essa imagem da escassez, da água que não se vê. Da água do corpo. A gente tem noção de que o nosso corpo é água quando a gente sua, chora, sangra, saliva, goza... Lembrando que a palavra é um corpo erótico e está toda inundada de água, mas, às vezes, essa água está quieta, está artesiana, no lençol freático, ela está dentro do corpo e não é visível. Eu acho que escrever é escavar essa palavra, essa força que não está dada, que às vezes só se revela pela angústia, quando um corpo chora, ou pela felicidade, ou pela emoção extrema do corpo, ou pelo movimento, pela dança, pelo gozo. Penso, sim, em não querer resolver nada com a poesia. A poesia não quer resolver nada. A linguagem cotidiana é a que quer resolver as coisas, que quer compreender tudo, colocar tudo dentro dos conformes e encaixotar. A poesia, não. Ela não quer resolver, não quer ser resolvida, não quer que ninguém a resolva. Sendo eu a escrever ou não, 
já deixaram muitos ecos dessa não resolução. O que a gente faz enquanto poeta é continuar afirmando que a palavra, dentro do campo da poesia, ela não vai afirmar nada. Ela é nula. Ela zera e entra no infinito. Ela só pode ser dentro do infinito. Por isso gera tanta potência (SÍNTIQUE, 2020).

Como visto, o corpo de referências aludido pela poeta culmina numa compreensão blanchotiana da palavra. Consciente de ser mais um dos ecos já cravados na história da literatura, Sara prossegue um projeto de irresolução que remete a tempos imemoriais, como tão bem exemplificam as obras e homenagens feitas a escritoras como Hilda Hilst ou Marguerite Duras. Trata-se de um diálogo autoconsciente em que se salienta não as poetas/falantes, mas a fala que delas provêm: "quando a neutralidade fala, somente aquele que lhe impõe o silêncio prepara as condições de escuta; e, no entanto, o que há para ser ouvido é aquela fala neutra, aquilo que sempre já foi dito, que não pode cessar de dizer-se e não pode ser ouvido" (BLANCHOT, 2005, p. 307). Uma imposição do falar e do calar que remete ao aforismo kafkiano e ao primeiro poema de sara em Água ou Testamento Lírico..., onde se problematiza uma sereia condenada ao canto, mas que ninguém ouve. Tal silenciamento é um malogro - para nos mantermos em um dos termos mais recorrentes ao imaginário de Blanchot, que também abre seu Livro por Vir com uma célebre seção sobre $O$ Canto das Sereias -, porém, tal experiência de queda e desgaste da linguagem se potencializa como um maior impulso para sua renovação. As noções de silêncio e nulidade aqui contempladas, apresentam-se em sua vertente mais produtiva, no que despertam das forças criantes que outrora localizamos nas águas e no psiquismo hidrante.

\section{Consideraçồes Finais}

É sobre um paradoxo que a transição de Blanchot a Barthes se sustenta. Em seu ensaio sobre A Busca do Ponto Zero, a respeito do seminal livro do colega (O Grau Zero da Escritura, original de 1953), ele localiza um grande projeto da literatura moderna, sobre o qual anexamos a trajetória poética de Sara Síntique: “'Escrever sem escrita', levar a literatura ao ponto de 
ausência em que ela desaparece, em que não precisamos mais temer seus segredos que são mentiras (...) a neutralidade que todo escritor busca, deliberadamente ou sem o saber, e que conduz a silêncios" (BLANCHOT, 2005, p. 303). Assim, concluímos que a condição escritural barthesiana é abraçada pela poeta na exata perspectiva adâmica que ela anuncia, de sonhar palavras felizes, de multiplicar ideais, de tornar-se a Utopia da Linguagem (BARTHES, 1974). Perpetuando a busca por palavras que instaurem o silêncio e que calem os ensurdecedores ruídos de dias secos e inférteis, Sara irmana seu corpo-verbo junto a vozes contemporâneas e autorreflexivas, espelhando linguagens que são adubo gota semente. Que mais ouvidos sejam alcançados por este silêncio, para que se invente o novo.

\section{Referências}

BACHELARD, G. A água e os sonhos: ensaio sobre a imaginação da matéria. 3. ed. Trad. Antonio de Pádua Danesi. São Paulo: Martins Fontes, 2018.

BARTHES, R. Novos ensaios críticos seguidos de o grau zero da escritura. Trad. Heloysa de Lima Dantas, Anne Arnichand e Álvaro Lorencini. São Paulo: Cultrix, 1974.

BLANCHOT, M. O livro por vir. Trad. Leyla Perrone-Moisés. São Paulo: Martins Fontes, 2005.

ECO, U. Sobre os espelhos e outros ensaios. Trad. Helena Domingos. Lisboa: DIFEL, 1989.

MERLEAU-PONTY, M. O visível e o invisível. 4. ed. Trad. José Artur Gianotti e Armando Moura d'Oliveira. São Paulo: Perspectiva, 2014.

SÍNTIQUE, S. Água ou testamento lírico a dias escassos. Fortaleza: Edições Ellenismos, 2019.

SÍNTIQUE, S. Corpo nulo. Fortaleza: Editora Substânsia, 2015. 